\title{
Educational attainment, deprivation-affluence and self reported health in Britain: a cross sectional study
}

\author{
Ian R White, David Blane, J N Morris, Philippe Mourouga
}

\begin{abstract}
Study objective-The level of material deprivation or affluence is strongly and independently correlated with all cause mortality at an area level, but educational attainment, after controlling for deprivation-affluence, remains strongly associated with coronary and infant mortality. This study investigated whether these relations hold at an individual level with self reported morbidity.

Design-Analysis of the cross sectional associations of self reported longstanding illness and "not good" or "fairly good" self assessed health with individual educational attainment in seven levels, adjusting for deprivation measures (economic status of head of household, car ownership, housing tenure, overcrowding).
\end{abstract}

Setting-The 1993 General Household Survey, a random sample of households in Great Britain.

Participants-11 634 subjects aged 22 to 69. Main results-After adjusting for household deprivation, lower educational attainment was significantly associated with longstanding illness in men (odds ratio 1.05 per education category, $95 \% \mathrm{CI} 1.02$ to 1.08 ), but not in women (odds ratio 1.01, $95 \%$ CI 0.98 to 1.04$)$. The associations with "not good" or "fairly good" self assessed

Medical Statistics

Unit, London School of

Hygiene and Tropical

Medicine, London

WC1E 7HT

I R White

Division of

Neuroscience,

Imperial College of

Science, Technology

and Medicine, London

D Blane

Health Promotion

Research Unit, London

School of Hygiene and

Tropical Medicine,

London

J N Morris

Service de

reanimation medicale,

Hopital Saint Louis,

Paris, France

P Mourouga

Correspondence to:

Mr I R White.

Accpeted for publication

11 February 1999 pathways through which social class could influence health. Current policy interest in the causes of social class differences in health in the United Kingdom makes an investigation of this issue timely. ${ }^{3}$ In earlier ecological analyses ${ }^{5}$ we used routinely available government statistics to estimate the relative contribution of education and deprivation to social variations in the chances of premature death. Level of deprivation or affluence was the stronger correlate of all cause mortality, while educational attainment was the stronger correlate of coronary heart disease and infant mortality. However, the results differed when different deprivation indices were used. ${ }^{6}$ The Department for Education's data on educational attainment referred to adolescents of 15 to 16 years, while the great majority of the premature deaths recorded in the Office for National Statistics' data had occurred among adults who were considerably older. A direct causal relation between education and health in our earlier analyses was therefore impossible. To pursue the issue individual level data on educational attainment, deprivation-affluence and health are required.

Other studies have gone some way towards investigating this question. Deprivationaffluence, measured in a variety of ways, and educational attainment are independently related in the British birth cohort studies to many aspects of health, but even the oldest of these studies has yet to age far into the second half of life. ${ }^{7}$ The ONS Longitudinal Study has shown that male adult mortality varies with both educational attainment and occupational social class, but the data set does not hold information on deprivation-affluence so it is not possible to analytically separate this dimension from the educational component of social class. ${ }^{8}$ The West of Scotland Collaborative Study found occupational social class to be a better discriminator of socioeconomic mortality differentials than age at leaving full time education, but like the ONS Longitudinal Study it lacked information on deprivationaffluence and hence was unable to disentangle the two relevant dimensions of social class. ${ }^{9}$

The General Household Survey avoids these problems. It holds detailed information on many aspects of the education and living standards of people of all ages resident in a random sample of the households in England, Wales and Scotland. Unfortunately neither mortality data nor objective measures of health are available for the General Household Survey sample, so users of the health aspects of this 
Table 1 Self reported longstanding illness and general health by sex

\begin{tabular}{|c|c|c|c|c|c|c|c|c|}
\hline & \multicolumn{8}{|c|}{ General health in the past 12 months (\% of all men / all women) } \\
\hline & \multicolumn{2}{|l|}{ good } & \multicolumn{2}{|c|}{ fairly good } & \multicolumn{2}{|l|}{ not good } & \multicolumn{2}{|c|}{ Total (\%) } \\
\hline \multicolumn{9}{|l|}{ Men } \\
\hline No longstanding illness & 2860 & & 550 & & 52 & & 3462 & (63) \\
\hline Non-limiting longstanding illness & 510 & & 283 & & 52 & & 845 & (15) \\
\hline Limiting longstanding illness & 312 & & 440 & & 423 & & 1175 & (21) \\
\hline Total $(\%)$ & 3682 & $(67)$ & 1273 & (23) & 527 & (10) & 5482 & $(100)$ \\
\hline \multicolumn{9}{|l|}{ Women } \\
\hline No longstanding illness & 3061 & & 758 & & 113 & & 3932 & $(64)$ \\
\hline Non-limiting longstanding illness & 458 & & 332 & & 79 & & 869 & $(14)$ \\
\hline Limiting longstanding illness & 300 & & 530 & & 521 & & 1351 & (22) \\
\hline Total $(\%)$ & 3819 & $(62)$ & 1620 & $(26)$ & 713 & $(12)$ & 6152 & $(100)$ \\
\hline
\end{tabular}

Percentages may not add up to $100 \%$ because of rounding.

data set are forced to rely on measures of self reported health. In consequence the present analyses of General Household Survey data complement, not replace, those from the other studies previously discussed.

\section{Methods}

We used data from the 1993 General Household Survey, which surveyed 24079 people in 9852 British households. ${ }^{11}{ }^{11}$ Subjects were asked about self assessed health ("Over the last 12 months would you say your health has on the whole been good, fairly good or not good?"), longstanding illness ("Do you have any longstanding illness, disability or infirmity?"), and limiting longstanding illness ("Does this illness or disability limit your activities in any way?"). Reporting biases are likely to overestimate the association of lower levels of education and deprivation with limiting longstanding illness, but to underestimate their association with longstanding illness and self assessed health. ${ }^{12}$ To err on the side of caution we concentrated on analyses of longstanding illness and self assessed health. We combined "fairly good" with "not good" self assessed health for the purposes of analysis; combining "fairly good" with "good" yielded similar results but with wider confidence intervals.

We identified seven levels of educational attainment: degree; higher education below degree level; A level; five or more GCSE passes at grades A-C; 1-4 GCSE passes at grades A-C; GCSE passes at grades D-G or other qualifications; and no qualifications. All categories allowed equivalents, especially CSEs and GCEs for GCSEs. Subjects with foreign qualifications were excluded.

We assessed deprivation-affluence using the same four variables that make up the Townsend Deprivation index. ${ }^{2}$ The Townsend index was designed to be computed at an area level, using binary indicators. To obtain better characterisation of a single household we made fuller use of the variables, coding economic status of head of household as employed, seeking work or economically inactive; persons per room in quartiles; and car ownership as none, one, and two or more. As in the Townsend index, tenure was coded as owner occupied or not.

A household's level of deprivation or affluence was additionally assessed by whether or not the household's residence contained central heating; the number of consumer durables owned by the household (from the following list: colour television, video recorder, freezer, washing machine, tumble drier, dishwasher, microwave oven, telephone, CD player, home computer); and household income. Household income was adjusted for household composition by the method of McClements, ${ }^{13}$ which divides total household income by the total "equivalence number" of all household members, to give the income of an equivalently well off couple without dependants; adjusted incomes were divided into quintiles. Registrar General's social class was also recorded.

We excluded subjects aged 70 years and older as they had not been asked to report their educational level. We also excluded subjects aged 21 years and younger, because a substantial proportion of this group would not yet have completed their education. Twenty per cent of the remaining subjects were excluded, because of missing values on one or more variables, mostly household income, leaving 11634 subjects (5482 men and 6152 women) in 6323 households.

Each health measure was used in turn as the dependent variable in a logistic regression. As age was strongly related to health it was entered as linear, quadratic and cubic terms, to completely remove confounding. The number of consumer durables was entered as a linear term. All other variables were entered as categorical variables but trend tests were performed for educational attainment, persons per room and car ownership.

Our main analysis entered age, education and the four Townsend deprivation variables into a single model. Poor health may lead a person to withdraw from the labour market, so a form of reverse causation is likely to occur for heads of household. We tackled this in three ways. Firstly, we constructed an alternative measure of deprivation-affluence, replacing the economic status of the head of household with household income, central heating and the number of consumer durables. Secondly, we removed from the analysis all households whose head was economically inactive. Thirdly, we removed all heads of household from the analysis.

\section{Results}

Thirty six per cent of the sample reported a longstanding illness and the same percentage assessed their health as less than good (table 1). Despite the virtually identical proportions, 
Table 2 Long standing illness by deprivation factors and education (mutually adjusted)

\begin{tabular}{|c|c|c|c|c|c|c|c|c|}
\hline & \multicolumn{4}{|l|}{ Men } & \multicolumn{4}{|l|}{ Women } \\
\hline & Number & $O R$ & $(95 \% C I)$ & $p$ value & Number & $O R$ & $(95 \% C I)$ & $p$ value \\
\hline \multicolumn{4}{|c|}{ Economic status of head of household } & \multicolumn{4}{|l|}{$<0.001$} & \multirow[t]{4}{*}{$<0.001$} \\
\hline Employed & 3828 & 1 & & & 4008 & 1 & & \\
\hline Unemployed & 491 & 1.29 & $(1.05,1.59)$ & & 441 & 1.07 & $(0.86,1.33)$ & \\
\hline Economically inactive & 1163 & 2.60 & $(2.19,3.09)$ & & 1703 & 1.50 & $(1.29,1.75)$ & \\
\hline \multicolumn{4}{|l|}{ Persons per room } & \multirow[t]{5}{*}{0.43} & & & & \multirow[t]{5}{*}{0.07} \\
\hline $0-0.39$ & 1208 & 0.90 & $(0.76,1.06)$ & & 1417 & 1.02 & $(0.88,1.18)$ & \\
\hline $0.40-0.50$ & 1651 & 1 & & & 1873 & 1 & & \\
\hline $0.51-0.71$ & 1249 & 0.85 & $(0.72,1.01)$ & & 1328 & 0.93 & $(0.79,1.09)$ & \\
\hline $0.72+$ & 1374 & 1.02 & $(0.87,1.21)$ & & 1534 & 0.87 & $(0.74,1.02)$ & \\
\hline \multicolumn{4}{|l|}{ Car ownership } & \multirow[t]{4}{*}{0.40} & & & & \multirow[t]{4}{*}{$<0.001$} \\
\hline 0 & 852 & 1.22 & $(1.02,1.46)$ & & 1300 & 1.31 & $(1.12,1.53)$ & \\
\hline 1 & 2707 & 1 & & & 2924 & 1 & & \\
\hline $2+$ & 1923 & 1.06 & $(0.93,1.21)$ & & 1928 & 0.86 & $(0.75,0.98)$ & \\
\hline \multicolumn{4}{|l|}{ Housing tenure } & \multirow{3}{*}{0.62} & & & & \multirow[t]{3}{*}{0.001} \\
\hline Owner occupied & 4095 & 1 & & & 4464 & 1.00 & & \\
\hline \multirow{2}{*}{\multicolumn{4}{|c|}{ Education }} & & 1688 & 1.26 & $(1.09,1.45)$ & \\
\hline & & & & \multirow[t]{9}{*}{0.001} & & & & \multirow[t]{9}{*}{0.71} \\
\hline degree & 745 & 0.69 & $(0.56,0.85)$ & & 458 & 1.06 & $(0.84,1.34)$ & \\
\hline below degree & 670 & 0.78 & $(0.64,0.97)$ & & 645 & 0.95 & $(0.77,1.16)$ & \\
\hline A level & 790 & 0.94 & $(0.77,1.15)$ & & 554 & 0.92 & $(0.74,1.16)$ & \\
\hline GCSE $5+\mathrm{A}-\mathrm{C}$ & 658 & 0.95 & $(0.77,1.16)$ & & 670 & 0.94 & $(0.77,1.15)$ & \\
\hline GCSE $1-4 \mathrm{~A}-\mathrm{C}$ & 379 & 0.76 & $(0.58,0.99)$ & & 716 & 1.09 & $(0.89,1.33)$ & \\
\hline GCSE D-G / others & 635 & 1.03 & $(0.85,1.26)$ & & 819 & 1.00 & $(0.84,1.20)$ & \\
\hline None & 1605 & 1 & & & 2290 & 1 & & \\
\hline \multicolumn{2}{|c|}{ Trend per education category } & 1.05 & $(1.02,1.08)$ & & & 1.01 & $(0.98,1.04)$ & \\
\hline
\end{tabular}

these two measures of health did not agree closely; 21 per cent of those who assessed their health as "good" also reported a longstanding illness and 36 per cent of those who assessed their health as "not good" or "fairly good" reported being free of longstanding illness.

In age adjusted analyses, each measure of deprivation and lower educational attainment was significantly associated with each measure of health for both men and women $(p<0.005$ in all cases), except that persons per room was not significantly associated with longstanding illness ( $p=0.10$ for men, $p=0.26$ for women).

The mutually adjusted relations between longstanding illness and the various measures of deprivation-affluence and educational attainment are presented as odds ratios (table 2). Among the measures of deprivation-affluence, economic status of the head of household is the main predictor for men, with the prevalence of longstanding illness raised in households with an unemployed head and more than doubled in households with an economically inactive head. The absence of car ownership is the only other predictor for men that is statistically significant, but number of cars owned does not show a significant trend relation. The odds of longstanding illness among men decrease with increasing levels of education, with an average odds ratio of $1.05(\mathrm{p}=0.001)$ comparing each category with the category immediately above it.

For women the relations with longstanding illness are somewhat different. The economic status of the head of household is still a significant predictor, but less strongly than among men. Both car ownership and housing tenure, however, among women show a significant relation with longstanding illness. Also unlike men, levels of educational attainment among

Table 3 "Not good" or "fairly good" self assessed health by deprivation factors and education (mutually adjusted)

\begin{tabular}{|c|c|c|c|c|c|c|c|c|}
\hline & \multicolumn{4}{|l|}{ Men } & \multicolumn{4}{|l|}{ Women } \\
\hline & Number & $O R$ & $(95 \% C I)$ & p value & Number & $O R$ & $(95 \% C I)$ & $p$ value \\
\hline \multicolumn{4}{|l|}{ Economic status of head of household } & \multirow[t]{4}{*}{$<0.001$} & & & & \multirow[t]{4}{*}{$<0.001$} \\
\hline Employed & 3828 & 1 & & & 4008 & 1 & & \\
\hline Unemployed & 491 & 1.15 & $(0.93,1.43)$ & & 441 & 1.10 & $(0.89,1.36)$ & \\
\hline Economically inactive & 1163 & 2.95 & $(2.47,3.51)$ & & 1703 & 1.53 & $(1.32,1.78)$ & \\
\hline Persons per room & & & & \multirow[t]{5}{*}{0.14} & & & & \multirow{5}{*}{0.10} \\
\hline $0-0.39$ & 1208 & 0.87 & $(0.73,1.03)$ & & 1417 & 0.97 & $(0.84,1.13)$ & \\
\hline $0.40-0.50$ & 1651 & 1 & & & 1873 & 1 & & \\
\hline $0.51-0.71$ & 1249 & 0.99 & $(0.83,1.18)$ & & 1328 & 1.07 & $(0.92,1.26)$ & \\
\hline $0.72+$ & 1374 & 1.02 & $(0.86,1.22)$ & & 1534 & 1.12 & $(0.95,1.31)$ & \\
\hline Car ownership & & & & \multirow[t]{4}{*}{$<0.001$} & & & & \multirow[t]{4}{*}{$<0.001$} \\
\hline 0 & 852 & 1.17 & $(0.98,1.40)$ & & 1300 & 1.38 & $(1.19,1.60)$ & \\
\hline 1 & 2707 & 1 & & & 2924 & 1 & & \\
\hline $2+$ & 1923 & 0.75 & $(0.65,0.86)$ & & 1928 & 0.82 & $(0.72,0.94)$ & \\
\hline Housing tenure & & & & \multirow[t]{3}{*}{0.002} & & & & \multirow[t]{3}{*}{$<0.001$} \\
\hline Owner occupied & 4095 & 1 & & & 4464 & 1 & & \\
\hline Rented & 1387 & 1.27 & $(1.09,1.48)$ & & 1688 & 1.41 & $(1.23,1.62)$ & \\
\hline Education & & & & \multirow[t]{9}{*}{$<0.001$} & & & & \multirow[t]{9}{*}{$<0.001$} \\
\hline degree & 745 & 0.45 & $(0.36,0.56)$ & & 458 & 0.51 & $(0.40,0.65)$ & \\
\hline below degree & 670 & 0.61 & $(0.49,0.76)$ & & 645 & 0.61 & $(0.50,0.75)$ & \\
\hline A level & 790 & 0.61 & $(0.50,0.75)$ & & 554 & 0.70 & $(0.56,0.87)$ & \\
\hline GCSE $5+\mathrm{A}-\mathrm{C}$ & 658 & 0.69 & $(0.56,0.85)$ & & 670 & 0.73 & $(0.60,0.89)$ & \\
\hline GCSE $1-4 \mathrm{~A}-\mathrm{C}$ & 379 & 0.60 & $(0.45,0.79)$ & & 716 & 0.87 & $(0.72,1.06)$ & \\
\hline GCSE D-G / others & 635 & 0.94 & $(0.77,1.14)$ & & 819 & 0.82 & $(0.69,0.97)$ & \\
\hline None & 1605 & 1 & & & 2290 & 1 & & \\
\hline Trend per education category & & 1.13 & $(1.09,1.16)$ & & & 1.11 & $(1.07,1.14)$ & \\
\hline
\end{tabular}


Table 4 Educational attainment by age and sex

\begin{tabular}{|c|c|c|c|c|c|c|c|c|c|c|c|c|}
\hline & \multicolumn{10}{|l|}{ Age } & \multirow{2}{*}{\multicolumn{2}{|c|}{ All ages }} \\
\hline & $22-29$ & & $30-39$ & & $40-49$ & & $50-59$ & & $60-69$ & & & \\
\hline \multicolumn{13}{|l|}{ Men } \\
\hline below degree & 109 & (11) & 214 & (16) & 192 & (15) & 90 & (9) & 65 & (7) & 670 & (12) \\
\hline A level & 229 & (23) & 242 & (18) & 175 & (14) & 104 & (11) & 40 & (4) & 790 & (14) \\
\hline GCSE $5+\mathrm{A}-\mathrm{C}$ & 182 & (18) & 176 & (13) & 149 & (12) & 103 & (11) & 48 & (5) & 658 & (12) \\
\hline GCSE $1-4 \mathrm{~A}-\mathrm{C}$ & 139 & (14) & 117 & (9) & 88 & (7) & 24 & (3) & 11 & (1) & 379 & (7) \\
\hline GCSE D-G / others & 101 & (10) & 131 & (10) & 108 & (8) & 138 & (14) & 157 & (18) & 635 & (12) \\
\hline None & 127 & (13) & 241 & (18) & 358 & (28) & 386 & (40) & 493 & (55) & 1605 & (29) \\
\hline All & 1016 & $(100)$ & 1342 & $(100)$ & 1279 & $(100)$ & 956 & $(100)$ & 889 & (100) & 5482 & $(100)$ \\
\hline \multicolumn{13}{|l|}{ Women } \\
\hline degree & 107 & (9) & 149 & (10) & 125 & (9) & 50 & (5) & 27 & (3) & 458 & (7) \\
\hline below degree & 97 & (8) & 193 & (12) & 172 & (12) & 100 & (10) & 83 & (8) & 645 & (10) \\
\hline A level & 213 & (19) & 180 & (12) & 105 & (7) & 32 & (3) & 24 & (2) & 554 & (9) \\
\hline GCSE $5+\mathrm{A}-\mathrm{C}$ & 185 & (16) & 190 & (12) & 160 & (11) & 58 & (6) & 77 & (7) & 670 & (11) \\
\hline GCSE $1-4 \mathrm{~A}-\mathrm{C}$ & 247 & (22) & 254 & (16) & 160 & (11) & 42 & (4) & 13 & (1) & 716 & (12) \\
\hline GCSE D-G / others & 152 & (13) & 186 & (12) & 192 & (14) & 147 & (15) & 142 & (13) & 819 & (13) \\
\hline None & 144 & (13) & 398 & (26) & 501 & (35) & 554 & (56) & 693 & (65) & 2290 & (37) \\
\hline All & 1145 & $(100)$ & 1550 & (100) & 1415 & $(100)$ & 983 & $(100)$ & 1059 & $(100)$ & 6152 & (100) \\
\hline
\end{tabular}

Percentages shown in parentheses.

women are not associated with the prevalence of longstanding illness; the average odds ratio for a 1-category decrease in education level is 1.01 and not statistically significant $(p=0.71)$. The odds ratios for educational attainment differ significantly between men and women $(\mathrm{p}=0.04)$.

The associations between limiting longstanding illness and education adjusted for age and deprivation are, as expected, rather stronger than for longstanding illness (results not shown): the odds ratio is 1.08 (95\% CI, 1.04 to 1.12 ) for men and 1.03 (0.99 to 1.07 ) for women.

The results for self assessed health are in many ways similar to those for longstanding illness but more pronounced (table 3 ). For both men and women, all the measures of deprivation-affluence, except persons per room, and educational attainment are significantly associated with "not good" or "fairly good" self assessed health status.

Educational level was strongly asociated with age - for example, the proportion with no educational qualifications was $13 \%$ at age $22-29$ but $61 \%$ at age $60-69$ (table 4 ). Despite this, the associations seen in tables 2 and 3 between educational level and health were the same at younger and older ages (results not shown).

When household equivalent income was added into the models in tables 2 and 3, it was associated weakly with longstanding illness and better self assessed health for both men and women. However, it was statistically significant only for women's self assessed health. Adjusting for income barely changed the associations, shown in tables 2 and 3, between educational attainment and health.

When social class was added into the models in tables 2 and 3 the odds ratios for each decreasing social class category were: for longstanding illness, 1.03 (95\% confidence intervals 0.98 to 1.09 ) for men and 1.06 (1.01 to 1.11) for women; and for "not good" or "fairly good" self assessed health, 1.07 (1.02 to 1.14 ) for men and 1.08 (1.03 to 1.13) for women. With adjustment for age only, the comparable odds ratios for each decreasing social class category were $1.13,1.12,1.28,1.24$ respectively, showing that between half and three quarters of the social class effect is explained by deprivation-affluence and educational attainment. Adjusting for social class slightly reduced the associations shown in tables 2 and 3 between educational attainment and health.

Table 5 summarises the further analyses that were undertaken to investigate the potentially distorting effect of "reverse causation" (that is, the head of household's health influencing their economic activity status) on the measures of deprivation-affluence. Firstly, the economic status of the head of household was removed from the models presented in tables 2 and 3 and replaced with alternative measures of deprivation-affluence. Household income, but not central heating or consumer durables, was highly significant. The effect on the association between education and the measures of health,

Table 5 Summaries of education effect allowing for reverse causation

\begin{tabular}{|c|c|c|c|c|c|c|c|c|c|}
\hline \multirow[b]{2}{*}{ Adjustment for reverse causation } & \multicolumn{4}{|l|}{ Men } & \multicolumn{4}{|l|}{ Women } & \multirow{2}{*}{$\frac{\text { Men v women }}{p \text { value }}$} \\
\hline & Number & $O R$ & $(95 \% C I)$ & p value & Number & $O R$ & $(95 \% C I)$ & p value & \\
\hline \multicolumn{10}{|l|}{ Long standing illness } \\
\hline None & 5482 & 1.05 & $(1.02,1.08)$ & 0.001 & 6152 & 1.01 & $(0.98,1.04)$ & 0.71 & 0.04 \\
\hline New deprivation model ${ }^{\star}$ & 5482 & 1.05 & $(1.02,1.08)$ & 0.002 & 6152 & 1.00 & $(0.97,1.04)$ & 0.79 & 0.05 \\
\hline \multicolumn{10}{|c|}{ Drop households with economically } \\
\hline inactive head & 4319 & 1.03 & $(0.99,1.06)$ & 0.10 & 4449 & 1.00 & $(0.97,1.04)$ & 0.98 & 0.27 \\
\hline \multirow{2}{*}{\multicolumn{10}{|c|}{ "Not good" or "fairly good" self assessed health }} \\
\hline & & & & & & & & & \\
\hline None & 5482 & 1.13 & $(1.09,1.16)$ & $<0.001$ & 6152 & 1.11 & $(1.07,1.14)$ & $<0.001$ & 0.35 \\
\hline New deprivation model ${ }^{\star}$ & 5482 & 1.11 & $(1.08,1.15)$ & $<0.001$ & 6152 & 1.09 & $(1.06,1.12)$ & $<0.001$ & 0.38 \\
\hline \multicolumn{10}{|l|}{ Drop households with economically } \\
\hline inactive head & 4319 & 1.08 & $(1.05,1.12)$ & $<0.001$ & 4449 & 1.09 & $(1.05,1.13)$ & $<0.001$ & 0.77 \\
\hline Drop heads of household & 526 & 1.15 & $(1.03,1.29)$ & 0.01 & 4785 & 1.10 & $(1.06,1.14)$ & $<0.001$ & 0.44 \\
\hline
\end{tabular}

^Replacing economic status of head of household with income, consumer durables, and central heating. 
however, was small. Secondly, households with economically inactive heads were dropped from the analysis. This reduced all of the associations between educational attainment and health, to the extent that statistical significance was lost for male longstanding illness (odds ratio reduced from 1.05 to $1.03, p=0.10$ ). The difference between the effects of education on longstanding illness for men and women also lost statistical significance, indicating greater compatibility between results for men and women. Thirdly, all heads of household were dropped from the analysis. This had little impact on the magnitude of the associations for men or for women. However, the remaining sample of men was very small and all confidence intervals were much widened: the association with longstanding illness lost statistical significance while the association with self assessed health was just strong enough to retain statistical significance.

\section{Discussion}

Educational measures are commonly used as markers of socioeconomic circumstances. For example, in 1989-90, mortality rates were 2.3 times higher in US men aged 25-64 with 9-11 years of education than in those with 16 or more years of education; the corresponding ratio for women was $1.6 .{ }^{14}$ In the Netherlands, self rated health less than "good" was 2.2 times more common in adults with primary education compared with those with university education. $^{15}$

More detailed data and analysis are required to identify the separate effects of education and deprivation on health. We used the General Household Survey, a large random sample of households that collects detailed information on many aspects of material deprivation and affluence as well as data on educational qualifications and self reported morbidity and health.

We concentrated our analyses on the measures of health where reporting bias is least likely to exaggerate relations. ${ }^{12}$ Rates of longstanding illness will underestimate the size of social variations in health because the clinical iceberg will be smaller among the more affluent and better educated. Self rated health will also provide underestimates because of the more ambitious benchmark against which the socially advantaged tend to judge their health.

Standard measures of deprivation are designed for use at an area level. To adjust fully for deprivation, we followed other authors ${ }^{16}$ in adjusting for each of the four deprivation measures separately.

Worse self assessed health in men and women is associated in our analyses, independently of deprivation, with lower levels of education; and independently of education, with greater material hardship on each indicator of deprivation apart from residential crowding. In contrast, the associations with longstanding illness differ for men and women. The prevalence of longstanding illness among men increases, independently of deprivation, with lower educational levels; but, independently of education, with only one of the indicators of deprivation, economic activity of head of household.
KEY POINTS

- Educational achievements of young people seem to correlate at an area level with adult mortality, independently of deprivation.

- We therefore investigated in depth whether a similar association holds with adult health in the General Household Survey.

- Longstanding illness (for men only) and "fair" or "poor" general health (for both sexes) were significantly associated with lower educational level.

- The associations were stronger for general health than for longstanding illness and stronger for men than for women.

- However, the association of health with deprivation-affluence is stronger than any effect of education.

Among women the prevalence of longstanding illness is not related, independently of deprivation, to the level of educational qualifications; and higher prevalence is associated with greater material hardship on each indicator of deprivation apart from residential crowding.

However, these results were derived from cross sectional data, so alternative explanations need to be examined. In our first analyses we treated the economic activity status of the head of household as an indicator of deprivationaffluence, with the implicit assumption that it could causally affect health. However, part of the association between economic activity and health, at least for heads of household, may reflect causation in the opposite direction, with ill health leading some heads of household to become economically inactive. As 90 per cent of the men but only 22 per cent of the women in this data set are heads of household, any effect will be strongest among men. If this reverse causation acted uniformly, it would inflate the regression coefficient for economic inactivity and correspondingly reduce the regression coefficients for the variables associated with economic inactivity. The effect of ill health on economic inactivity, however, is not uniform; it varies with social position and is greatest among those with least education and the most physically demanding work. ${ }^{17}$ Because of the greater demands of working life, this effect differentially moves ill people with lower education from economic activity to economic inactivity, weakening the association between education and health in the economically active and strengthening it in the economically inactive.

We tackled the problem of reverse causation in three ways. Firstly, we developed an alternative deprivation model that replaced the economic activity variable with household income, central heating and consumer durables. Reverse causation may still act through these proxies, for example, illness may cause household income to decrease, but the effect should be weaker. On the other hand, omitting economic activity may lead to the effect of deprivation being inadequately controlled. In 
fact, the results with this approach were little different from the original analysis.

Secondly, we excluded all people with an economically inactive head of household, thus probably underestimating the associations between educational attainment and health. The effect was to reduce but not eliminate the observed associations between education and health and to just remove statistical significance for longstanding illness among men $(\mathrm{p}=0.10)$.

Thirdly, we excluded all heads of household from the analysis. In principle this is the ideal method but it leaves very small numbers of men. The association of education with longstanding illness again lost statistical significance among men; the association with self assessed health remained statistically significant although with much widened confidence intervals. The results for women were little changed.

These analyses suggest that reverse causation has only a small effect on the associations between education and health reported in tables 2 and 3.

We excluded $20 \%$ of subjects from these analyses because of missing data (mostly on household income). This could cause bias but only if non-responders differed from responders both in their education and in their level of health.

DIFFERENCES BETWEEN HEALTH MEASURES

The differences between the results for self assessed health and for longstanding illness are surprising. In the absence of a satisfactory explanation, the results for longstanding illness should probably be given priority. Longstanding illness can be equated with chronic disease; self assessed health lacks a comparable clinical equivalent and varies independently of the more clinically plausible longstanding illness measure.

One possible explanation is that while longstanding illness largely indexes physical health, self assessed health may also be indexing psychological health, which is more strongly associated with social circumstances. ${ }^{18} \mathrm{~A}$ review of 27 studies found that poorer self assessed health consistently predicts mortality, even after adjustment for specific symptoms and diseases, and suggested that this may be because self assessed health better captures a person's health state or health trajectory, or because self assessed health measures external or internal resources for coping with future illness or for adopting health related behaviours. ${ }^{19}$ The latter possibilities would agree with the idea that self assessed health indexes psychological as well as physical health. However, other studies have shown that self assessed health is most strongly associated with physical health experience. ${ }^{20}{ }^{21}$ Psychosocial factors may influence "better than average" self assessed health more strongly than "worse than average" self assessed health, the measure used in the present study. ${ }^{21}$

The differences between the results for men and women are also surprising, although the associations between educational attainment and health were not significantly different in men and women after reverse causation was allowed for. An analogous finding is that mortality rates of married women are better predicted by their husband's occupation than their own occupation. ${ }^{22}$ Self assessed health seems to predict mortality more strongly in men than in women ${ }^{19}$ but is roughly equally associated with health symptoms, ${ }^{20}$ thus suggesting that self assessed health is a comparable measure in men and women; we are not aware of similar studies for longstanding illness. One possible explanation of any differences is that some type of illness that is strongly related to education is more common in men than in women. However, the most probable explanation is that educational attainment is a weaker determinant of life chances for married women than for men.

\section{INTERPRETATION}

Taken together, our results in relation to self reported health indicate an association, independent of deprivation-affluence, between educational attainment and adult health. We have discussed elsewhere ${ }^{6}$ the various mechanisms by which higher levels of education could be associated with better health:

(1) The material and cultural resources of the family of origin are a powerful influence on educational attainment, so educational level will act as a marker of childhood socioeconomic circumstances. The association between educational attainment and adult health could be attributable to the influence of childhood socioeconomic circumstances and nutrition on adult health.

(2) Educational qualifications are a powerful predictor of labour market position during the years of working life, so educational attainment will act as a marker of adult socioeconomic circumstances. The association between educational attainment and adult health could be attributable to the influence of adult socioeconomic circumstances on adult health.

(3) Educational attainment may reflect a person's capacity to absorb new information and to act on it. The association between educational attainment and adult health could be attributable to the influence of education on the adult propensity to adopt health education advice in relation to, for example, cigarette smoking, leisuretime exercise and dietary choice.

(4) The association between educational attainment and adult health could be confounded by some relatively stable psychological characteristic, such as time preference or self efficacy, which influences both the capacity to pursue formal education during childhood and adolescence and the capacity to maintain health during adulthood.

(5) Ill health during childhood could both limit educational attainment and predispose to ill health in adult life.

We have argued previously ${ }^{6}$ that probably the fourth and fifth explanations have little effect. We have gone some way in the present analyses towards eliminating the second explanation, although our measures of deprivation- 
affluence during adulthood will have largely missed the psychosocial aspects of work such as demand-control imbalance, effort-reward imbalance, social status and self esteem, and physicochemical hazards such as dust and fume exposures. On this reading, then, the relation, independent of deprivation-affluence, between educational attainment and adult self assessed health could be attributable to the influence of socioeconomic circumstances during childhood, aspects of the work environment during adulthood or the influence of education on the propensity to adopt health education advice.

Childhood and adult nutrition are important determinants of adult health. However, it would be inappropriate to adjust for nutrition because it may be one of the causal pathways between education/deprivation and adult health.

To investigate further these relations, and to disentangle the often contradictory results given by the different self reported measures of health, future research requires individual level information on educational attainment and deprivation-affluence that is as rich as the General Household Survey's plus objective measures of health. The small size of the effect of income over and above deprivation variables was surprising and also deserves further research.

In conclusion, socioeconomic status has various correlated dimensions, including material deprivation and educational attainment, which may relate to different measures of health in different ways. Studies of socioeconomic determinants of health commonly rely on educational attainment, ${ }^{14} 2324$ but educational attainment should be regarded only as a proxy measure of socioeconomic status, which should be supplemented by direct measures of material deprivation. Our analysis of the separate dimensions has suggested that educational attainment may influence health independently of material deprivation, although the association of health with deprivation-affluence is stronger than any effect of education.

We thank Mel Bartley and Amanda Sacker for very helpful discussions. Material from the General Household Survey made available through the Office of Population Censuses and
Surveys and the ESRC data archive has been used by permission of the Controller of $\mathrm{H}$ M Stationery Office, but the analysis and interpretation of the data are the responsibility of he authors alone.

Conflicts of interest: none.

1 Halsey AH, Heath AF, Ridge JM. Origins and destinations: family, class and education in modern Britain. Oxford: family, class and educatic

2 Townsend P, Phillimore P, Beattie A. Health and deprivation: inequality and the North. London: Croon Helm, 1988.

3 Department of Health. Government takes action to reduce health inequalities. Department of Health Press Release 97/192, 1997

4 Hansard. Health inequality. London: House of Commons, 25 February 1998: 281-300

5 Morris JN, Blane DB, White IR. Levels of mortality, education, and social conditions in the 107 local education authority areas of England. 7 Epidemiol Community Health 1996;50:15-17.

6 Blane D, Morris J, White I. Education, social circumstances and mortality. In: Blane D, Brunner E, Wilkinson R, eds. Health and social organisation. London: Routledge; 1996: 171-87.

7 Kuh D, Wadsworth MEJ. Physical health status at 36 years in a British national birth cohort. Soc Sci Med 1993;37: in a British

8 Goldblatt P, ed. Mortality and social organisation. LS series No.6. London: HMSO, 1990

9 Davey Smith G, Hart C, Hole D, et al. Education and occupational social class: which is the more important indicator of mortality risk? I Epidemiol Community Health 1998;52: 153-60.

10 Foster K, Jackson B, Thomas M, et al. General Household Survey 1993. London: HMSO, 1995.

11 Office of Population Censuses and Surveys Social Survey Division. General Household Survey 1971- (computer file). Colchester: ESRC data archive, 1994

12 Blane D, Power C, Bartley M. Illness behaviour and the measurement of class differentials in morbidity. Fournal of the Royal Statistical Society A 1996;159:77-92.

13 McClements L. Equivalence scales for children. Fournal of Public Economics 1977;8:191-210.

14 National Centre for Health Statistics. Health United States 1993. Hyattsville, MD: Public Heath Service, 1994

15 Mackenbach JP. Inequalities in health in The Netherlands according to age, gender, marital status, level of education, degree of urbanisation and region. European fournal of Public Health 1997;3:112-18.

16 Sloggett A, Joshi H. Higher mortality in deprived areas: community or personal disadvantage? BMF 1994;309: 1470-4.

17 Bartley M, Owen C. Relation between socioeconomic status, employment and health during economic change, 1973-93. BMF 1996;313:445-8.

18 Brown GW, Harris T. The social origins of depression. London: Tavistock, 1978.

19 Idler EL, Benyamini Y. Self-rated health and mortality: a review of twenty-seven community studies. I Health Soc Behav 1997;38:21-37.

20 Fylkesnes K, Forde OH. The Tromso study: predictors of self-evaluated health - has society adopted the expanded health comcept? Soc Sci Med 1991;32:141-6.

21 Smith AMA, Shelley JM, Dennerstein L. Self-rated health: biological continuum or social discontinuity? Soc Sci Med 1994;39:77-83.

22 McDowall M. Measuring women's occupational mortality. Popul Trends 1983; 34:25-9.

23 Rogot E, Sorlie PD, Johnson NJ, et al. A mortality study of 1.3 million persons by demographic, social and economic factors: 1979-1985 follow-up. NIH publication no. 92-3297. 1979-1985 follow-up. NIH publication no. 92

24 van der Meer JBW, Mackenbach JP. Course of health status among chronically ill persons: differentials according to level of education. F Clin Epidemiol 1998;51:171-9. 